\title{
Erratum to: Microfabricated glass devices for rapid single cell immobilization in mouse zygote microinjection
}

\author{
Xinyu Liu • Yu Sun
}

Published online: 19 September 2009

(C) Springer Science + Business Media, LLC 2009

Erratum to: Biomed Microdevices

DOI 10.1007/s10544-009-9333-5

The original version of this article unfortunately contained a mistake. The caption to Figure 2 was incorrect. The full caption in its correct form is as follows.

Fig. 2 Microfabrication process $(\mathbf{a}-\mathbf{c})$. \footnotetext{
org/10.1007/s10544-009-9333-5

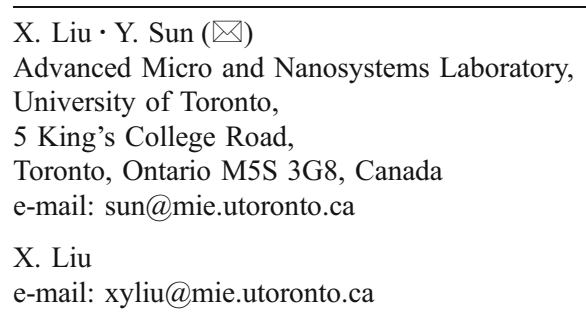

The online version of the original article can be found at http://dx.doi. 